\title{
PERANCANGAN SISTEM INFORMASI PENDATAAN PENDUDUK KELURAHAN SUNGAI JERING BERBASIS WEB DENGAN OBJECT ORIENTED PROGRAMMING
}

\author{
Febri Haswan \\ Fakultas Teknik, Universitas Islam Kuantan Singingi \\ J1. Gatot Subroto KM.7 Jake, Teluk Kuantan Riau \\ Email : febri.haswan88@gmail.com
}

\begin{abstract}
Abstrak
Kantor Lurah Sungai Jering merupakan salah satu instansi dibawah naungan pemerintah Kabupaten Kuantan Singingi, dalam pengolahan data penduduk Kantor Lurah Sungai Jering masih menggunakan cara konvensional sehingga mengakibatkan pekerjaan menjadi kurang efektif dan efisien, data penduduk ini sangat diperlukan untuk mengetahuai berapa jumlah warga tiap RT yang ada di Kelurahan Sungai Jering, dengan adanya sistem yang dirancang ini dapat memudahkan pekerjaan bagian pendataan penduduk dalam mengelola data dengan lebih efektif dan efisien tanpa harus merekap kembali data penduduk tiap RT yang ada di Kelurahan Sungai Jering, aplikasi ini dapat digunakan dimana saja asalkan terhubung pada jaringan internet petugas dapat menginputkan data secara langsung melalui aplikasi yang dibuat tanpa harus merekap kembali data menggunakan Microsoft Excel karena aplikasi ini sudah merekap data secara otomatis, selain itu warga juga dapat melihat informasi tentang data penduduk di Kelurahan Sungai Jering.
\end{abstract}

Kata Kunci : Perancangan Sistem Informasi, Object Oriented Programming, Website

\begin{abstract}
The Sungai Jering Village Office is one of the agencies under the auspices of the Kuantan Singingi District Government. In processing the population data, the Sungai Jering Village Office still uses conventional methods so that the work becomes less effective and efficient, this population data is needed to find out how many residents there are in Sungai Jering Subdistrict, with this system designed to facilitate the work of the population data collection section in managing data more effectively and efficiently without having to recapitulate the population data of each RT in Sungai Jering Village, this application can be used anywhere as long as it is connected to the network internet officers can input data directly through applications that are made without having to recapitulate data using Microsoft Excel because this application has already taped data automatically, besides that residents can also see information about population data in Kelurahan Sungai Jering.
\end{abstract}

Keywords : Information System Designing, Object Oriented Programming, Website 


\section{PENDAHULUAN}

Perkembangan teknologi sekarang ini semakin cepat. Dengan kecanggihan teknologi saat ini kita dapat mempermudah perkerjaan yang akan dilakukan. Kita dapat mencari informasi yang kita butuhkan serta kita dapat memperluas jaringan komunikasi menggunakan kecanggihan teknologi. Salah satunya teknologi yang banyak digunakan saat ini oleh kalangan masyarakat adalah komputer.

Dengan memanfaatkan teknologi komputer kita dapat menyimpan, mengorganisasi dan melakukan pengambilan terhadap berbagai data yang kita miliki. Dengan dukungan perangkat lunak dan perangkat keras yang tepat. Dengan segala kecanggihan komputer saat ini banyak perusahan/lembaga yang memanfaatkan teknologi tersebut. Salah satunya yang menggunakan kecanggihan komputer adalah Kantor Lurah Sungai Jering Kabupaten Kuantan Singingi, Kantor Lurah Sungai Jering merupakan salah satu instansti pemerintahan dibawah naungan pemerintah Kabupaten Kuantan Singingi dengan pemanfaatan teknologi komputer pekerjaan tentang pengolahan administrasi sudah cukup baik, namun dalam pengelolaan data penduduk masih dilakukan dengan cara konvensional yaitu petugas kelurahan mendatangi rumah-rumah penduduk di Kelurahan Sungai Jering untuk melakukan pendataan sehingga waktu yang diperlukan tmenjadi tidak efisien, selain itu permasalahan tentang hilangnya data yang telah di data oleh petugas menjadi pekerjaan menjadi tidak efektif, tidak hanya itu dengan menggunakan cari seperti ini ada sebagian warga tidak terdata oleh petugas, seharusnya dizaman sekarang ini Kelurahan Sungai Jering telah memiliki sebuah sistem yang dapat memudahkan pekerjaan dalam pengolahan data penduduk di Kelurahan Sungai jering sehingga pekerjaan menjadi lebih efektif dan efisien.

\section{TINJAUAN PUSTAKA}

\subsection{Definisi Sistem Informasi}

Definisi sistem informasi dalam bukunya Abdul Kadir yang berjudul Pengenalan Sistem Informasi, yaitu : "Sistem informasi adalah kerangka kerja yang mengkoordinasikan sumber daya (manusia, komputer) untuk mengubah masukan (input) menjadi keluaran (informasi), guna mencapai sasaran-sasaran perusahaan”. (Kadir, 2003)

Penjelasan di atas menerangkan bahwa sistem informasi dapat mempermudah perusahaan dalam mencapai sasaran yang telah ditargetkan dengan mengkoordinasikan manusia dan komputer sebagai sumber daya untuk mengubah masukan menjadi pengeluaran yang diinginkan. Sistem informasi juga dapat memudahkan pekerjaan disuatu perusahaanperusahaan. 


\subsection{Komponen Sistem Informasi}

Sistem informasi dalam mendukung beberapa komponen yang fungsinya sangat vital di dalam sistem informasi. Komponen-komponen sistem informasi tersebut adalah Hardware, software, prosedur, pengguna dan data base. Secara rinci komponen- komponen sistem informasi dapat dijelaskan sebagai berikut :

a. Perangkat keras (Hardware), mencakup peranti-peranti fisik seperti monitor dan printer.

b. Perangkat lunak (software) atau program: sekumpulan intruksi yang memungkinkan perangkat keras untuk dapat memproses data

c. Prosedur: sekumpulan aturan yang dipakai untuk mewujudkan pemrosesan data dan pembamasyarakatn keluaran yang dikendaki.

d. Pengguna: semua pihak yang bertanggung jawab dalam pengembangan sistem informasi, pemrosesan, dan penggunaan keluaran sistem informasi.

e. Database: merupakan kumpulan dari data yang saling berhubungan dengan data lainnya, tersimpan diperangkat keras komputer dan digunakan perangkat lunak untukl memanipulsinya, diantaranya; data, user dan sistem. (Kadir, 2003:70)

Sistem informasi akan berjalan baik jika sistem informasi itu telah memiliki 5 (lima) komponen di atas diantaranya hardware dan software, prosedur, pengguna dan data base. Hardware atau perangkat keras terdiri dari computer dan printer. Dalam suatu komputer terdapat unit-unit yang bertujuan untuk memproses sesuatu ataupun data yang maysarakat inginkan.

Komponen-komponen tersebut sangat penting dalam suatu sinstem informasi, apabila salah satu komponen tidak ada maka sistem informasi tidak akan berjalan. Penggunaan sistem informasi dalam suatu organisasi atau sektor pemerintahan dapat meningkatkan kinerja dalam pelayanan publik agar suatu pelayanan dapat berjalan efektif dan efisien. Dalam prakteknya, tidak semua sistem informasi mencakup semua komponen yang telah disebutkan di atas. 


\section{METODE PENELITIAN}

Adapun metode dari penelitian ini dapat penulis uraikan dalam bentuk diagram alur seperti dibawah ini.

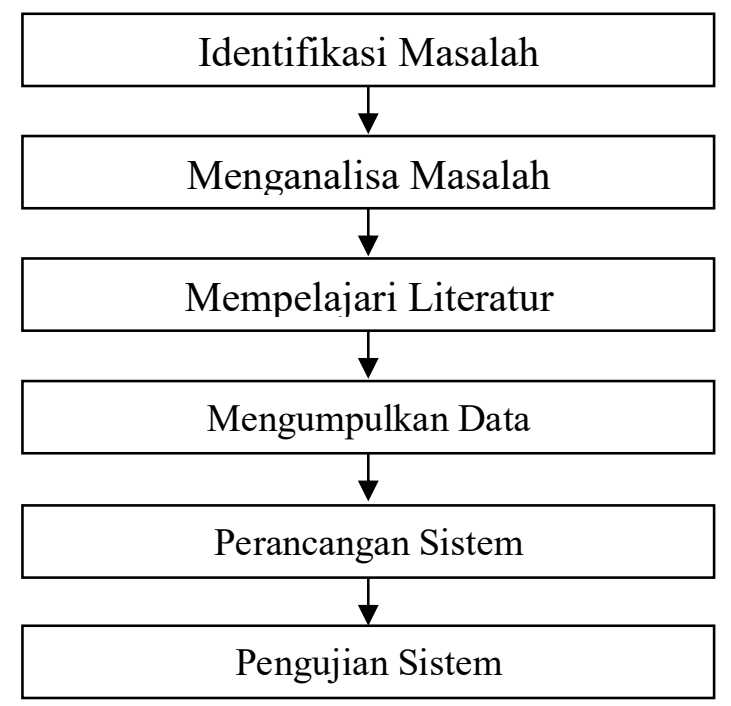

\section{Gambar 3.1 Diagram Alur Kerja}

Tahapan - tahapan rancangan penelitian :

1. Identifikasi Masalah

Pada tahap ini dilakukan peninjauan pada masalah yang akan diteliti untuk mengamati dan melakukan eksploitasi dan mengkaji lebih dalam tentang permasalahan yang ada pada saat ini. Tahap ini merupakan langkah awal untuk menemukan rumusan masalah yaitu bagaimana merancang sebuah sistem informasi berbasis web menggunakan metode OOP yang akan digunakan dalam perancangan sistem.

2. Menganalisa Masalah

Setelah kita mengetahui pokok permasalahan pada penelitian ini selanjutnya penulis menganalisa tahap-tahap dalam perancangan sistem guna menyelesaikan masalah yang ada pada Kantor Lurah Sungai Jering Kabupaten Kuantan Singingi.

3. Mempelajari Literatur

Agar penelitian ini menjadi maksimal langkah selanjunya penulis mencari referensi berupa buku-buku panduan, tutorial serta jurnal-jurnal dan penelitian terdahulu yang penulis dapat dari beberapa sumber.

4. Mengumpulkan Data

Dilakukan untuk memperoleh informasi atau data yang dibutuhkan dengan cara melakukan wawancara langsung pada bagian yang terkait yaitu Staf dan kkepala Bagian Umum pada kantor Lurah Sungai Jering. 
5. Perancangan Sistem

Setelah data terkumpul penulis melanjutkan perancangan sistem yang akan dibuat dengan mengambarkan rancangan apliasi berupa desain Output dan Input dalam pembuatan sistem informasi pendataaan penduduk Kelurahan Sungai Jering.

6. Pengujian Sistem

Setelah sistem selesai dibuat maka tahap selanjutnya akan dilakukan sebuah pengujian guna mencari kesalahan maupun kekurangan dalam perancangan sistem tersebut.

\section{HASIL DAN PEMBAHASAN}

\subsection{Analisa Sistem Yang Sedang Berjalan}

Sistem yang sedang berjalan dalam pendataan penduduk Kantor Lurah Sungai Jering dapat penulis gambarkan dalam bentuk aliran sistem informasi berikut ini :

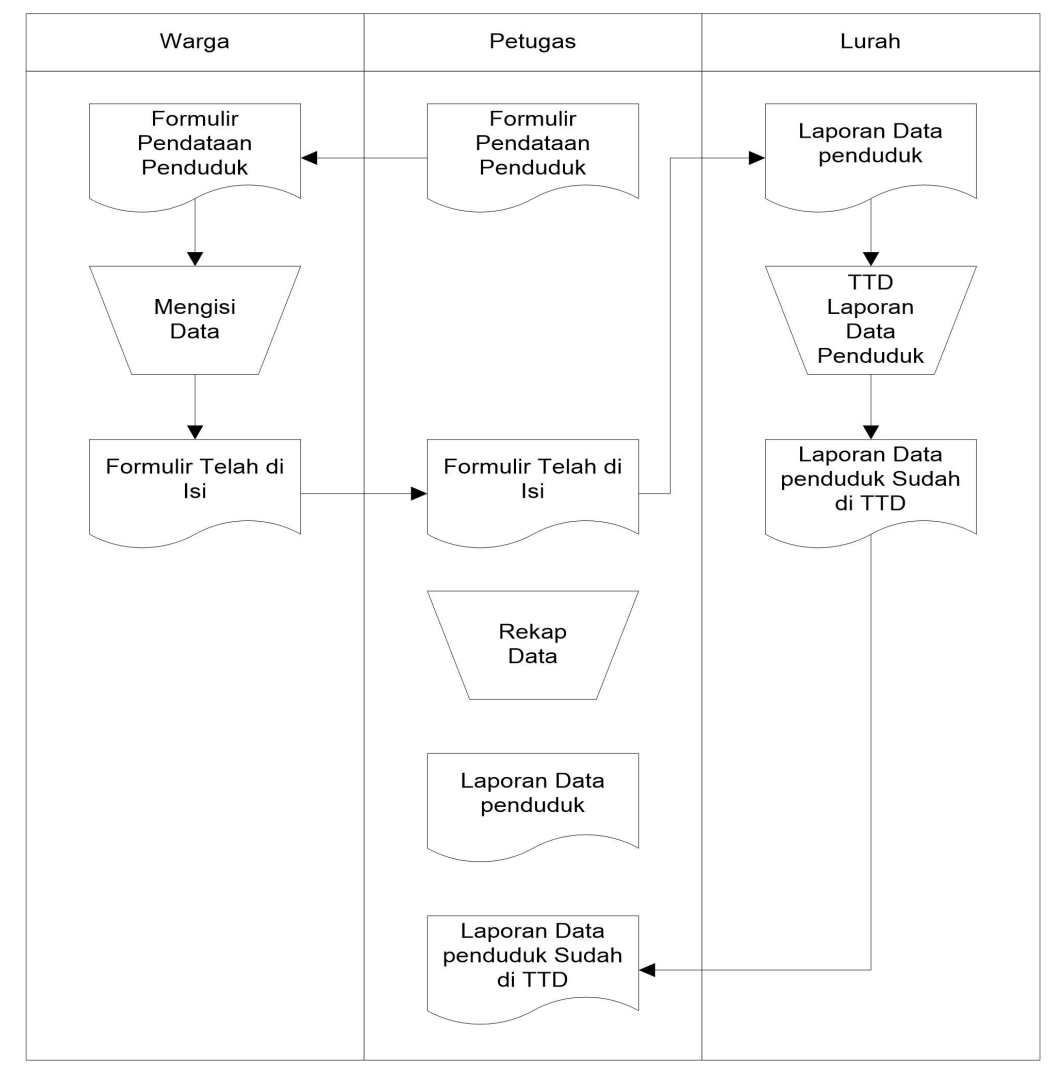

\section{Gambar 4.1 Aliran Sistem Informasi Yang Sedang Berjalan}

\subsection{Analisa Sistem Yang Sedang Berjalan}

Sebelum dilakukan perancangan terhadap sistem baru, perlu adanya gambaran mengenai sistem yang ada atau sistem yang sedang berjalan. Hal ini untuk memudahkan didalam melakukan perancangan sistem baru tersebut sehingga apa yang diinginkan dapat berjalan dengan baik. Dengan kata lain, sistem yang lama merupakan bahan perbandingan untuk merancang sistem yang baru. Gagasan untuk melengkapi sistem informasi timbul 
karena adanya permasalahan tentang pendataan pnduduk di Kelurahan Sungau Jering masih dilakukan dengan cara konvensional sehingga pekerjaaan para petugas pendataan penduduk menjadi tidak efektif dan efisien. Pekerjaan ini akan memakan waktu yang cukup lama dikarenakan petugas harus merekap data penduduk kembali menggunakan microsoft excel. Untuk lebih mempermudah perancangan sistem, perlu dilihat permasalahan dari sistem yang sedang berjalan saat ini dengan memperhatikan aliran informasi yang dimulai dari petugas memberikan formulir pendataan penduduk kepada warga dilingungan Kelurahan Sungai Jering.

\subsection{Use Case Diagram}

Adapun use case diagram Pendataan Penduduk Kelurahan Sungai Jering Berbasis Web ini sebagai berikut :

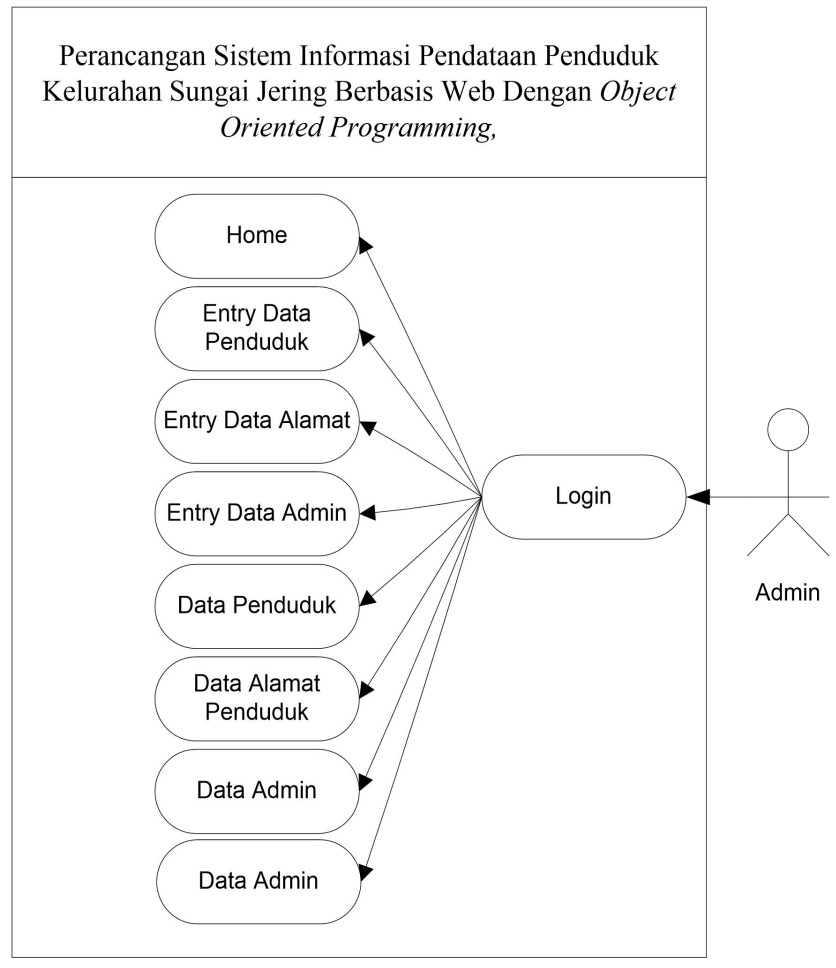

\section{Gambar 4.2 Use Case Diagram}

\subsection{Implementasi Sistem}

Implementasi sistem dilakukan dengan setiap halaman aplikasi yang dibuat dan pengkodeannya dalam bentuk file program. Berikut ini adalah implementasi sistem dalam Perancangan Sistem Informasi Pendataan Penduduk Kelurahan Sungai Jering Berbasis Web Dengan Object Oriented Programming. 


\section{Halaman Entry Data Penduduk}

Pada form entry data penduduk ini admin akan memasukan seluruh data penduduk di Kelurahan Sungai Jering.

\section{Entry Data Penduduk}

\begin{tabular}{ll|}
\hline NIK & \\
Nomor Kartu Keluarga & \\
Nama Lengkap & \\
Tempat Lahir & - \\
Tanggal Lahir & \\
Alamat & - Pilih - V \\
Jenis Kelamin & - Pilih - V \\
Agama & - Pilih - \\
Status & - Pilih - V \\
Pendidikan & - Pilih - - \\
Pekerjaan & Simpan Batal
\end{tabular}

Gambar 4.3 Halaman Entry Data Penduduk

\section{Halaman Entry Data Alamat Penduduk}

Pada form entry alamat penduduk ini admin akan memasukan seluruh data alamat penduduk di Kelurahan Sungai Jering.

\section{Entry Alamat Penduduk}

$\begin{array}{ll}\text { NIK } & 1409084607920001 \text { } \\ \text { Nama Desa } & \text { Sungai Jering } \\ \text { RT } & 002 \\ \text { RW } & : 001 \\ \text { Kecamatan } & \text { Kuantan Tengah } \\ & \text { Simpan Batal }\end{array}$

\section{Gambar 4.4 Halaman Entry Data Alamat Penduduk}

\section{Laporan Data Penduduk}

Laporan ini digunakan sebagai rekapitulasi oleh Kantor Lurah Sungai Jering dimana laporan ini dapat dicetak oleh admin pada aplikasi ini. 


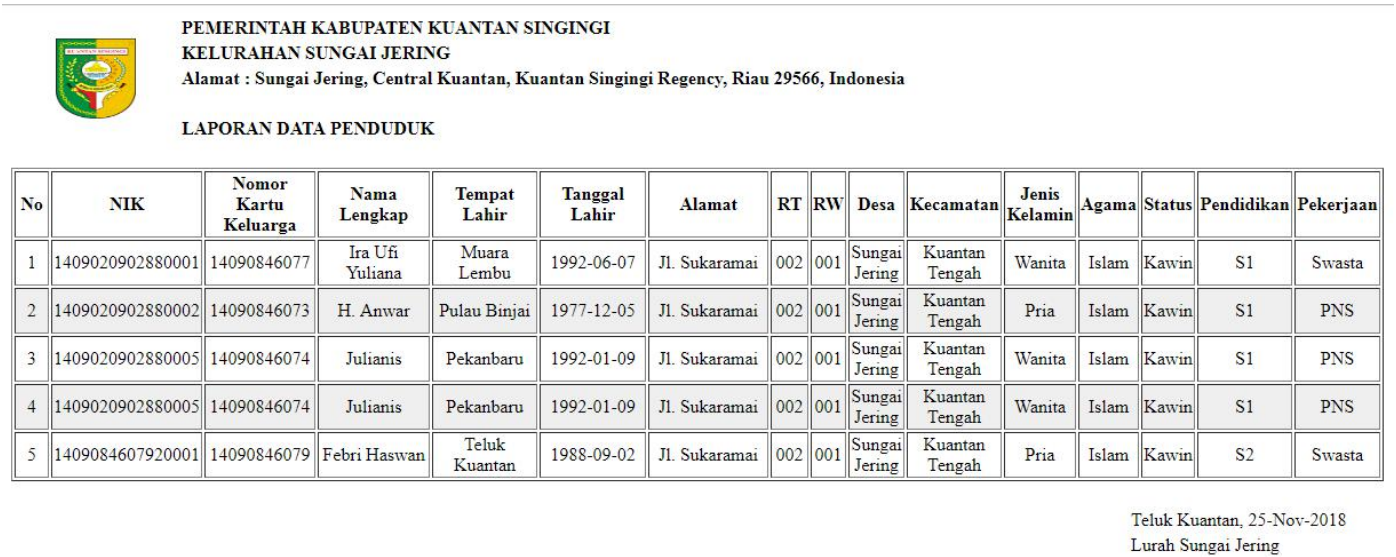

\section{Gambar 4.5 Laporan Data Penduduk}

\section{KESIMPULAN}

Adapun kesimpulan dari penelitian ini sebagai berikut :

1. Dengan adanya sistem ini dapat membantu Kantor Lurah Sungai Jering dalam pengolahan data penduduk di Kelurahan Sungai Jering menjadi lebih efektif dan efisien.

2. Dengan sistem ini data tersimpan dengan rapi dan dapat dilihat dimana pun berada.

3. Mengurangi kehilangan data yang selama ini sering terjadi.

\section{DAFTAR PUSTAKA}

Agustina Simangunsong. 2018. Sistem Informasi Pengarsipan Dokumen Berbasis Web. Jurnal Mantik Penusa, Vol. 2, No. 1 Juni 2018, pp.11-19.

Egia Rosi Subhiyakto.dkk. 2017. Rancang Bangun Sistem Informasi Pengarsipan Data Pasien Klinik Cemara. Techno.COM, Vol. 16, No. 1, Februari 2017 : 25-34.

Febri Haswan. 2015. Perancangan Website Sekolah Menengah Pertama (SMP) Sebagai Media Informasi Pada Masyarakat (Studi Kasus : SMPN 5 Teluk Kuantan). Jurnal SAINTIKOM UNIKS Volume 1, No. 1 Hal. 1 - 13.

Hariyanto, B. 2004. Rekayasa system berorientasi Objek”. Bandung: Informatika Bandung. Jogiyanto. 2003. Sistem Teknologi Informasill .Yogyakarta : Andi.

Marini. 2015. Perancangan Sistem Pendataan Penduduk pada Kelurahan Air Itam dengan Object Oriented. Jurnal Edukasi dan Penelitian Informatika (JEPIN) Vol. 1, No. 2, (2015).

Munawar. 2005. Pemodelan UML Berorientasi Objek. Jakarta:Andy Jogyakarta. 
Nofri Wandi Al-Hafiz, dan Febri Haswan. 2018. Sistem Informasi Monografi Kecamatan Singingi. Jurnal Instek Volume 3 Nomor. 1, April 2018. Hal. 1 - 10

Oki Vavilla dan Febri Haswan. 2016. Sistem Informasi Penggunaan Anggaran Dana Bantuan Operasional Sekolah (BOS) Pada SD Negeri 004 Gunung Toar. Jurnal SAINTIKOM UNIKS Volume 2, No. 2 Hal. 1 - 12.

Sutabri, T. 2012. Analisa Sistem Informasi. Jakarta : penerbit : Andi.

Sutabri, Tata ,"Konsep Sistem Informasi”, Penerbit Andi, Yogyakarta, April 2012. 